\title{
Re: Spirometry and peak flow in COPD
}

Dear Sir

Professor Gibson concluded with Kelly in their paper in 1988: ".. the apparently greater sensitivity of PEF monitoring in such patients probably reflects the frequency and timing of the measurements rather than any true difference in sensitivity between PEF and FEV ${ }_{1}$ " [1]. This paper is the only evidence in the BTS and GOLD guidelines to support the superiority of spirometry over peak expiratory flow (PEF) in COPD $[2,3]$. Their statement is the opposite of what was said in these guidelines. If there is no difference in sensitivity between the two measures then PEF is superior by virtue of being more accessible, more convenient, and no less reliable. However, as I make clear, there should be no argument that spirometry is a superior test to PEF in the diagnosis of COPD [4] The question for primary care is when and how spirometry should be done and whether PEF should have a role.

I am surprised that Professor Gibson thinks spirometry is not difficult to incorporate into a routine consultation. This is contrary to the ATS recommendations which suggest a five minute rest before the test [5]. It also ignores the physical demands of the test for people with impaired lung function. Spirometry may be feasible in routine consulting if it is being used to identify COPD in asymptomatic smokers. If the test is completely normal first time, many clinicians will not bother repeating it until three repeatable tests are obtained. If it is abnormal once it should always be repeated at least twice until three tests within ATS criteria are achieved. Spirometry is more taxing than PEF, and since coaxing the patient to exhale fully is an essential ele- ment of the test, patient fatigue is an important issue.

To recommend spirometry in routine consulting is a short-sighted strategy and one that fails to recognise the importance both of the test itself and of performing it effectively. If we try to incorporate spirometry into the consultation, we may end up doing spirometry badly, and that is not a better option than doing PEF welt [6]. If we want a screening tool for COPD, then PEF does the job [7]. Diagnosis is the second step, and one that deserves good quality spirometry. How to monitor COPD is another question altogether and one which may include PEF in the answer.

\section{References}

[1] Kelly CA, Gibson GJ. Relation between FEV and peak expiratory flow in patients with chronic airflow obstruction. Thorax 1988;43:335-6.

[2] Pauwels RA, Buist AS, Ma P, Jenkins CR, Hurd SS. Global strategy for the diagnosis, management, and prevention of chronic obstructive pulmonary disease: National Heart, Lung, and Blood Institute and World Health Organization Global Initiative for Chronic Obstructive Lung Disease (GOLD): executive summary. Respir Care 2001;46(8):798825.

[3] BTS guidelines for the management of chronic obstructive pulmonary disease. The COPD Guidelines Group of the Standards of Care Committee of the BTS. Thorax 1997; 52(Suppl 5):S1-28.

[4] White PT. Spirometry and peak expiratory flow in the primary care management of COPD. Primary Care Respiratory Journal 2004;13:5-8.

[5] Committee on Proficiency Standards for Clinical Pulmonary Function Laboratories, Americal Thoracic Society. Standardization of Spirometry. Am J Respir Crit Care Med 1995;152: $1107-36$ 
[6] Eaton T, Withy S, Garrett JE, Mercer J, Whitlock RM, Rea $\mathrm{HH}$. Spirometry in primary care practice: the importance of quality assurance and the impact of spirometry workshops. Chest 1999;116(2):416-23.

[7] Jackson H, Hubbard R. Detecting chronic obstructive pulmonary disease using peak flow rate: cross sectional survey. BMJ 2003;327(7416):653-4.
Patrick White

Department of General Practice and Primary Care, 5 Lambeth Walk, London SE116SP, UK

Tel.: +44 2078484188; fax: +44 2078484102 E-mail address: patrick.white@kcl.ac.uk

27 July 2004

Available online at www.sciencedirect.com

science@direct. 